\title{
UN INTERESANTE IMPRESO FILIPINO DE MEDIADOS DEL SIGLO XVIII
}

\section{Por Ernesto Lemoine $V$.}

LA Guerra de sucesión española, que en Utrecht liquidó una serie de mitos políticos, cuyos orígenes podian hacerse remontar sin mucho esfuerzo al tiempo -físico y moral- de los Reyes Católicos, legó a España, entre otras cosas, aparte de una nueva dinastía sustentada en la premisa de "Ya no hay Pirineos", el siniestro inventario de un patrimonio en bancarrota, al cual se adjuntaba una especie de "última voluntad" que imponía la obligación de renivelarlo, a cualquier precio, como condición imperativa para preservar la existencia de la monarquía.

Del cumplimiento o incumplimiento de tal testamentaría dependía el porvenir de un vasto imperio, en cuantos aspectos conformaban su esencia y su presencia y su proyección en el ámbito de la Historia. Mas la dura prueba y el pesado fardo se sortearon con éxito, y en el diario quehacer de los nuevos dirigentes, la mies recogida fue tan abundante, que el mundo hispánico, cabalgando sobre el lomo del ilustrado siglo xviı, aseguró así otro centenario - el último- de saludable y bien nutrida longevidad.

En tres importantes direcciones irradió el programa gubernamental de los Borbones: taponar el tremendo boquete que a la estructura del Estado le había causado la desventurada administración de los postreros Habsburgos; recuperar el crédito que como potencia mundial perdiera el país, en lento declive, a partir del reinado de Felipe III; $y$, por último, introducir a España, en calidad de socio activo, al recinto moderno, racional y científico, del Siglo de las Luces, donde ya tomaban asiento los países más cultos de Europa, encabezados por sus despóticos e ilustrados soberanos y por sus altruistas y dedicados sabios; ello, aun cuando hubiera necesidad de demoler las murallas que, según idea generalizada, encerraban al español en una serie de anacrónicos complejos: su peninsularidad, su imperturbable tradición y su intolerancia religiosa e ideológica.

El último aspecto es el que nos interesa destácar por lo pronto. Asienta el erudito don Agustín Millares Carlo, a propósito del insigne polígrafo Feyjoo: "Su constante esfuerzo sembró là semilla que, andando el tiempo, había de dar resultados tan beneficiosos como la fundación de la Academia de Nobles Artes de San Fernando (1753); la re- 
forma de los Colegios Mayores, defendida desde 1771 por Pérez Bayer y no implantada hasta 1777; la creación, en 1770, de los Reales Estudios de San Isidro; la apertura, en 4 de noviembre de 1776, del Gabinete de Historia Natural, dirigido por Bowles, y la inauguración, años después (1787), de la primera cátedra de Química del reino, desempeñada por don Pedro Gutiérrez Bueno. Las enseñanzas filosóficas fueron gradualmente libertándose del yugo escolástico y las matemáticas cultivadas con entusiasmo en los Colegios de Guardias Marinas, Artillería de Segovia (1764) y Escuelas militares de Ávila y Ocaña. El estudio detenido de la multitud de problemas, ideas y orientaciones apuntadas por el autor del Teatro Critico nos hace comprender mejor las causas del resurgimiento cultural de (España) durante el reinado de Carlos III." 1

Es un grupo selecto - de Feyjoo a Jovellanos, para citar linderos en el tiempo a una misma corriente intelectual-, el que se echa a cuestas la tarea de europeizar a España, desarraigándola de su aferramiento peninsular (forma casi acabada de insularidad). Estos quijotes de la modernidad, puntualiza Jean Sarrailh, "eran pocos; no formaban sino un intrépido puñado que no temía los golpes y que, cuando no podía trabar batalla a la luz del sol, sabía retroceder y burlar las emboscadas del enemigo. Si no contaba con verdaderas falanges más que en Madrid y en las primeras ciudades del reino, tenía tiradores esparcidos por todas partes; y su fuerza venía de esta dispersión". 2

Precisamente. Uno de esos tiradores se apostó en las remotas Filipinas y desde ahí disparó su dardo, en pleno reinado de Fernando VI, como para demostrar que el espiritu ilustrado, afín a la época y consustancial a ella, no se detenía en la Corte ni en los principales burgos de la Península, sino que cruzaba los océanos y se manifestaba hasta en los más remotos lugares de aquella unidad política cuya divisa se hizo universalmente famosa con el sólo emblema de Plus Ultra. Porque lo notable de esta saludable política radica en que su fomento no se limitó a la cabeza de la monarquía; irradió a la periferia -y la ecúmene hispánica abarcaba todavía entonces un respetable número de grados terrestres-, dándose el caso de que el impacto de la innovación fuese a menudo más resonante en las zonas marginales que

1 Prólogo al Teatro critico universal, "Clásicos Castellanos", Ediciones de "La Lectu ra". Madrid, 1923, t. 1. pp. 50-1.

2 La España ilustrada de la segunda mitad del siglo xvit, trad. de Antonio Alatorre, Fondo de Cultura Económica, México, 1957, p. 709. 
en la misma metrópoli, quizás por ser más inesperado y por tenerse en aquéllas una idea harto humilde del interés que las mejoras espirituales de sus moradores podían despertar en el ánimo de los graves funcionarios de Madrid.

El aporte filipino a la marejada renovadora del xvill, de que nos ocupamos ahora, es un impreso acompañado de precioso grabado, casi hermano de otro, glosado y analizado en estos mismos Anales, con su sabroso estilo y su reconocida autoridad, por el doctor Francisco de la Maza. ${ }^{3} \mathrm{El}$ nuestro es, cronológicamente, un poco anterior, y por su largo y cadencioso título el lector se percatará al instante del tema que trata. Helo aquí:

\section{CONCLVSIONES}

MATHEMATICAS,

PRACTICAS, Y ESPECVLATIVAS

DEFENDIDAS

EN EL PRINCIPIO DEL SEGVNDO AÑO

POR

DON FERNANDO DE ARAYA, ALFEREZ DE VNA DE LAS COMPANIAS DEL REGIMIENTO DEL REY NVESTRO SEFOR, PRESIDIENDO

EL R. P. FRANCISCO ORTIZ SVGASTI, PROFESSOR PVBLICO DE MATHEMATICAS

EN LA VNIVERSIDAD DE LA COMPANIA DE IESVS de esta Ciudad de Manila.

Con las lizencias necessarias en Manila en la Imprenta de la Compañia de IESVS, por D. Nicolas de la Cruz Bagay. Año de 1758.

La pieza de referencia, impresa en formato pequeño, consta de nueve fojas, las cinco primeras sin numeración y las cuatro últimas numeradas del 1 al 4. La anteportada se llena con un dibujo que representa al rey Fernando VI a caballo; sigue la portada, con el título del opúsculo y el pie de imprenta en el anverso de la hoja (que transcribimos arriba) y el largo encabezado de la Dedicatoria en el reverso, cuyo texto comprende las subsecuentes tres hojas; por último, en las cuatro hojas finales

3 Véase, "Aspecto simbólico del mundo hispánico. Un grabado filipino del siglo xvin" en Anales del Instiluto de Investigaciones Estéticas, nủm. 33, México, 1964, pp. 5-2I. 
se hallan las Conclusiones Mathemáticas propiamente dichas. Un ejemplar de esta rareza bibliográfica se guarda en el Archivo General de la Nación, de donde obtuvimos las fotocopias que se incluyen. ${ }^{4}$

En tres breves apartados lo analizaremos: la dedicatoria, las conclusiones matemáticas y el grabado.

a) La Dedicatoria. El encabezado de la misma lo reproducimos en facsímil al lado de la portada: el texto, en cambio, hemos optado por transcribirlo, modernizando su ortografía, a continuación de este breve estudio, debido a que lo apelmazado de la letra, la transparencia del papel en que fue impreso y, consecuentemente, el emplaste de las tintas de ambas caras, hacen algo ilegible y poco práctica su presentación facsimilar. Lo que interesa es conocer el escrito, las finalidades que alegó el autor para darlo a la prensa, y su carácter, tan representativo de una época y tan manifiesto de la cortesanía exhibida por cierto tipo de intelectuales, de aquél y de todos los tiempos, para ganar los favores del gobernante en turno, llámese Rey, Primer Ministro, Jefe del Estado o Presidente.

El autor es don Fernando de Araya, "Alférez de una de las Compañías del Regimiento del Rey Nuestro Señor", que presentó sus Conclusiones en un acto celebrado por la "Academia de Matemáticas" o de "Militares", recientemente fundada en Manila, en la "Universidad de la Compañía de Jesús" presidiendo el "R.P. Francisco Ortiz Zugasti, Profesor Público de Mathemáticas" de la misma Universidad. Ya de por si es relevante que en Manila hubiera Academia de Matemáticas en 1758, cuando no la había en ninguna de las grandes capitales de los virreinatos americanos y cuando en la misma Metrópoli, a lo que sabemos, no funcionaba todavía, formalmente y con el padrinazgo real, un instituto de esa naturaleza. ${ }^{3}$ No importa que la susodicha Academia haya trabajado bajo muy modestas aspiraciones -como a gritos lo exhibe ésta, su primera publicación oficial, que es casi un manualito destinado a

4 Ramo Impresos Oficiales, t. v, exp. 15. Agradecemos al señor Melchor Garcia Reinoso, Jefe del Departamento de Gráficas de la Secretaría de Hacienda, el interés que manifestó para que en la dependencia a su digno cargo se hiciran las fotocopias dc nuestro impreso.

5 En una obra plagada de errores, hallamos este dato que no hemos podido comprobar en otras fuentes: "Felipe II, después de fundar la Academia de Matemáticas, ofreció un premio de 6,000 ducados de renta perpetua, que se aumentaron a 2,000 más de renta vitalicia, al que descubriera el modo de calcular la longitud por medios astronómicos, acudiendo sabios de todos los países, sin que ninguno aventajase a España". V. Peset, Lo que debe a España la cultura mundial, Javier Morata Editor, Madrid, 1930, pp. 126-27. 
niveles de enseñanza elemental- ni que careciera de un respetable equipo de sabios de fama mundial. Lo que cuenta es la idea y el clima espiritual que la hace posible: un público ávido de saber, un reducido grupo de enterados dispuestos a trasmitir generosamente sus conocimientos, y unos funcionarios (desde el monarca hasta el último alcalde mayor) entusiasmados con la misión a que se les orilla de ser patronos de la cultura.

La Dedicatoria de Araya, dirigida por supuesto al munificente Fernando VI, barroca y conceptual en grado superlativo, es una lagrimeante apología a la Ciencia de las Matemáticas y una interminable catarata de piropos al real y poderoso personaje que dio su apoyo para que en las remotas Filipinas se creara un organismo dedicado a su estudio y propagación; y el autor acude a todos los resortes de su ingenio para tocar las cuerdas sensibles del monarca, con miras a no perder el valioso mecenazgo que la flamante institución filipina disfrutaba desde su erección. El estilo literario, ampuloso y reiterativo, es cabalmente el mismo del que pocos años después se burlarían los espíritus selectos del neoclasicismo: "Según Cadalso (Cartas Marruecas), los títulos de los libros aparecidos entonces se parecen a éstos: Médula eutrapélica que enseña a jugar a las damas con espada y broquel añadida y aumentada; Arte de bien hablar, freno de lenguas, modelo de hacer personas, entretenimiento útil y camino para vivir en paz; Nueva mágica experimental y permitida; Ramillete de selectas flores asi aritméticas como fisicas, astronomicas, astrológicas, graciosos juegos repartidos en un manual Kalendario para el presente año de 1761". "

No seamos tan cáusticos como Cadalso, máxime si advertimos que el esfuerzo de Araya fue del todo inútil. Su retorcida y salomónica apología llegó a Madrid en mal momento: acababa de morir la reina, doña Bár. bara de Braganza, y el regio viudo no quería enterarse ya de nada, ni siquiera de los gorgoritos atenorados de su dilecto Farinelli. Transido de pena, se apoderó de su ánimo "una profunda tristeza; dirigióse al palacio de Villaviciosa acompañado de su hermano el cardenal Luis, se encaró en una estancia, y alli, sordo a todos los consuelos, sin querer ver a nadie, entregado a su dolor y casi sin tomar alimento, le atacó una atonía fatal... Hizo testamento... y dio el último suspiro el 10 de agosto de $1759 \%$. ' Y Araya, a su vez, aguardando en su gabinete matemático

6 Citado por Fernando Díaz-Plaja, La vida española en el siglo xvil, Editorial Alberto Martín, Barcelona, 1946, p. 165.

T Manuel Ortiz de la Vega, "Crónica de las Dinastías Austriaca y Borbónica", en Las Glorias Nacionales. Grande Historia Universal de todos los reinos, provincias, 
de Manila el efecto de su Dedicatoria, al saber la muerte del destinatario (que además era su tocayo), fuera de sí, arrojaría pluma, regla, compás y escuadras, y habría deseado que uno de esos tifones del Pacífico meridional lo arrastrara hasta sus más recónditas profundidades.

Pero otro, un colega suyo, recogería al punto el hilo de la inspiración decepcionada de don Fernando, y desde la misma Manila gritaría: " $₫ E 1$ Rey ha muerto! . . iViva el Rey!"; y, ni tardo ni perezoso, se apresuraria a remitirle al nuevo sol que se levantaba por sobre las crestas de la Sierra de Guadarrama, una producción más ambiciosa que la destinada a Fernando VI, con un grabado gigantesco (una verdadera sábana pictórica) y toda una señora disertación de Theses Mathemáticas: Imprenta, la misma de Nicolás de la Cruz Bagay; firmante: don Vicente de Memije; finalidades: idénticas a las que animaron al precedente; resultados: mejores, pues a Carlos III en 1761 le restaban aún 27 años de vida y de reinado. Quien desee enterarse del eco que este segundo florilegio filipino tuvo en el ánimo del mejor de los borbones españoles, no tiene más que acudir a las amena y aguda reconstrucción imaginada por De la Maza.

b) Las Conclusiones Mathemáticas. Divididas por su autor en cuatro incisos, a saber "Geometría Elemental", "Geometría Práctica", "Globo Terrestre" y "Deducciones del Globo Terretre pertenecientes a la Statica", no son más que simples ejercicios acedémicos, destinados, presuntamente, a alumnos de nivel inferior al universitario. Los temas expuestos con criterio didáctico, muestran uno de los múltiples tópicos de la enseñanza científica que inquietaban a los hombres del xvirl. Su inserción en el presente estudio, por lo mismo, es aconsejable; máxime que la claridad del original permite imprimirlo en facsímil, agregando así a la simpática lectura de las cuestiones apuntadas por Araya, el sabor de época que nos brindan siempre este tipo de trabajos.

c) El grabado. Con mucho, lo más interesante de nuestro impreso filipino es el dibujo que lo acompaña y que ocupa todo la primera plana. Enmarcado en una sencilla orla rectangular, lo primero que llama la atención es la figura ecuestre de Fernando VI, colocada al centro y apoyada sobre dos mundos que se ven ceñidos por helicones, de cuyas amplias bocinas se elevan ondulantes columnas de nubes o incienso, en dirección convergente hacia la cabeza del monarca. Cada columna es portadora de una leyenda bíblica, escrita en latín que, traducidas, dicen, la

islas y colonias de la monarquia española, desde los tiempos primitivos hasta el año de 1854, Librería de la Publicidad-Librería Histórica, Madrid, 1854, t. ri, p. 433. 


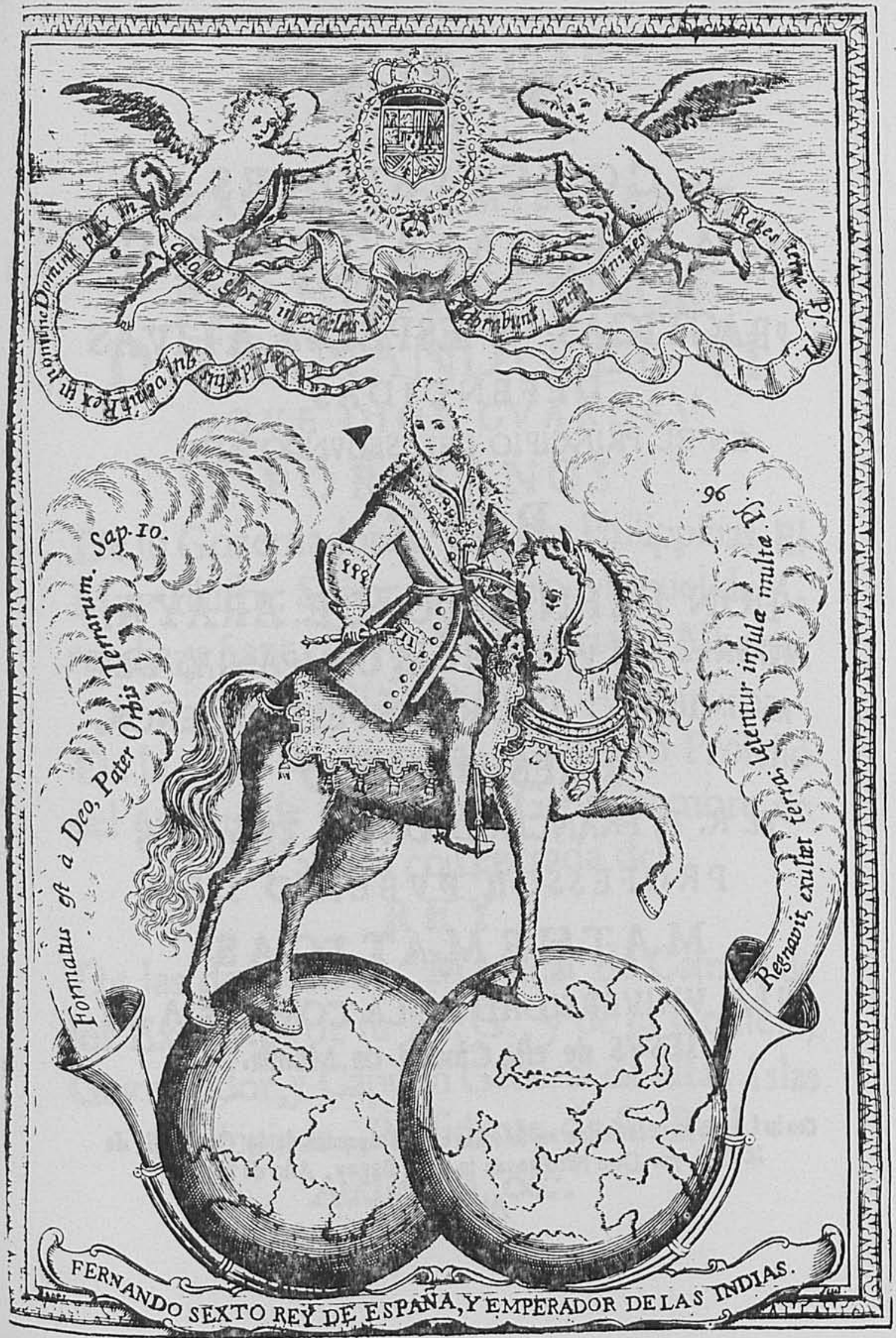




\section{as $\sqrt{2}$ s0 \\ CONCLVSIONES \\ MA THE MA I ICA S, \\ PRACTICAS, Y ESPECVLATIVAS \\ DEFENDIDAS}

EN EL PRINCLIPIO DEL SEGUNDO AÑO

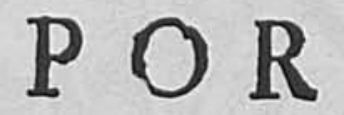

\section{DON FERNANDO DE, ARAYA.} ALFEREZ DE VNA DE LAS COMPANIAS DEL REGIMIENTO DEL REY NVESTRQ SEÑOR,

\section{PRESIDIENDO}

EL R. P. FRANCISCO ORTIZ ZVGASTI,

PROFESSOR PUBLICO DE MATHEM AT PCAS

ENLA VNIVERSIDAD DE LA COMPANIIA DE IESUS de efta Ciudad de Manila.

Con las Lizencias necefTarias ea Mavila es la Imprenta de la Compañia do iLSVS, por Dos Nicolas de la Cruz Bagay. Año de 1758 . 


\section{DEDICALAS LA}

ACADEMIA DE MILITARES $A L$

$$
\begin{aligned}
& \text { REY NVESTRO SEÑOR } \\
& \text { D. FERNANDO EL VI. } \\
& \text { (QVE DIOS GVARDE) } \\
& \text { POR MANOS }
\end{aligned}
$$

De fu Governador de las Islas Philippinas, BI Muy Illuitre Seńor D. Pedro Manuel de A. randia,y Santeftevan Echeverria, y Álberro:

$$
\text { SEÑ OR }
$$

De la Cafa de Arandia, Cavallero Proferfó del Orden de Calatraba, Gentsl hombre de Camara con eatrada del

\section{REY}

De las dos Sicilias, Marifcal de Campo de los Exercitos de fu M. G., y de fu Conlejo, Governador,y Capitan General de eftas Islas Philippinas, Prefidente de fu Real Audiencia, \&xc. 
Pag. 1.

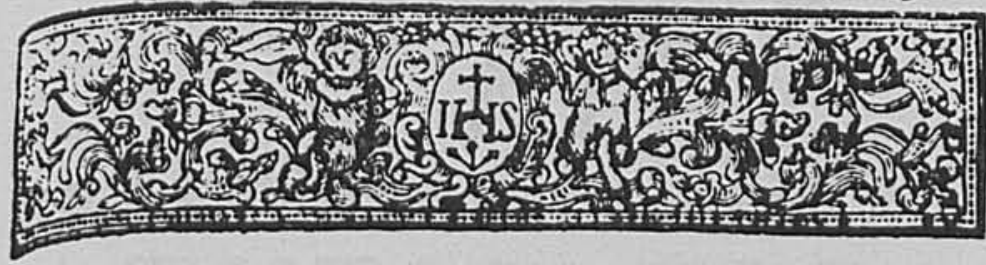

CONCLVSIONES MATHEMATICAS.

\section{S. I. \\ GEOMETRLA ELEMENTAL.}

4. . defcribir va triangulo equilatero.

$s_{i}$

Partir un angulo dado ea dos prr. ies iguales.

j. Si una recta cae fobre otra, hace dos angu, los recros, 0 dos iguales à dos rectos.

4. Alargado un lado de un rriangalo, el angulo externo es igual à los dos interiores opurefios.

5. Los paraklogrammos, que tiene una mifritu, ò igual bala, y eftan eutre uthas mifmas parale. las, fon iguales; lo inifmo es de los tríangalos. * El lado opuefto al angulo recto en el rrian. gulo recaangulo muttiplicado por $f$, hace un quadrado igual à los quadrados de los otros dos lados juntamente tomados.

7. Cortar una linea de modo, que el rectangu. to de elles, y un fegmetroc fea igual al quadrado 


\section{CONCLVSIONES}

del otro legmento.

8. Hallar el centro de un circulo dado.

9. Dado un arco, faber de que circulo es areo.

30. El angulo que fe forma en el cenero es do. ble del que fe forma en la circunferencia,quan. do los dos tienes un milmo arco por bafa.

11. El angulo, que efta en el femicirculo es ree. to; el que en el fegmento maior que el femi circulo, es agudo; y el qque en el fegmento me. nor, es obtufo.

12. Silas cantidades divididas, fon proporcia nales tambien lo feràn compueftas.

13. Si de dos rodos fe reftan dos cantidades, que tienen entre fi la mifna razon, que los todos, tambien los refiduos tendran la mifina razon, $^{2}$ que los todos.

14. En quatro cantidades proporcionales, la maxima, y la minima juntas fon maiores que las otras.

15. Si der tro de un triargulo fe tira una paraleta à la bafa, cortara los lados del triangulo en proporcion.

16. Los triangulos equiangulos tienen lus lados proporcionales.

37. Si dos planos fe cortan, fu comun feccion 


\section{MATHEMATICAS.}

es una linea recta.

if Las rectas perpendiculares aun milmo pla. no fon entre fi paralelas.

19. La linea, que junta dos puntos de dos para. lelas efta con ellas en un mifno plano.

20. Si dos rectas, que concurren en un plano fon paralelas à dos, que concurren-en otro; formaràn angulos iguales.

21. Si â dos rectas cortan planos paralelos las cortaràn proporcionalmente.

\section{- $\simeq$ ઈ. II.}

GEOMETRIA PRACTICA.

I.

Ividir una linea seata en qualefquiera partes iguales, ò defiguales.

9. Infcribir dentro de un circulo qualefquiera figuras regulares.

3. Dados qualefquiera rectilineos iregulares, hacer uno regular, que fea igual à todos.

4. Medir una linea Horizontal inaccefible.

5. Medir una alcura inaccefible.

Dels longi.

merris.

6. Medir una profundidad.

7. Hacer una defcripcion Ichnographica.

8. Medir la fuperficie de qualefquiera Poligo De le Pla. nos, Circulos, Prifmas, Piramides, y Conos. 


\section{CONCLVSIONES}

8. Medir la fuperficie de las espheras. De'as sre- 10. Medir la folidez de los cubos, de los parz lelipipedos, de lus prifmas, y de los cylindsos.

11. Medir la folidez de una esphera.

\section{III. \\ ESPHERA.}

3. $E$ dara razòn de los Siltemas pertenecien, res à la efphera.

2. Explicacion del orden, y difpoficion de las efpheras, y fus circulos.

3. Rejila general, para faber en que figno, o grasto de ls ecliptica eltà el Sol en qualquiera

- exs, òjia del añan

4. Porer la eiphera en la recitiud debida.

5. Saber por cl globo Celefte la eftrella, qus renernxos vercical, y la que nace por el Hori. zonxe dे qualquiera liora del dia, ò de la noche.

6. Ssber, que lea longitud, latitud, y declinaci. on de un aftro.

7. Sáser las afcenfiones de los aftros, y figoos, ò arcos de la ecliprica, y fus defcenfiones.

8. Hallar la declinacion del Sol, y fus amplieu. des.

9. Saber el punto del Orolcopo, 
MATHEMATICAS.

\section{y. IV. \\ GLOBO TERRESTRE. \\ 1. FXplicacion del globo terreftre, y fus Ecirculos.}

2 Saber por dicho globo el arco femidiurno, $y$ feminozurno, $y$ aे que hora nace, y fe pone el Sol.

3. Dada la hora en qualquiera Ciudad faber en que Regiones alumbra el Sol, y que hora es en qualquiera parte.

Saber la diferencia del maior dia del año entre dos Ciudades.

- Saber los Antipodas.

6. Sáber la longitud, y latitud de qualquiera logaro

7. Saber la duracion de los crepufculos en qualquiera Region, y la caula, porque algunas vezes fe varia la regla general.

$$
\text { S. V. }
$$

DEDVCCIONES DEL GLOBO TERRES TRE PERTENECIÉNTES

)*( ì la Statica. )*(

2. Odos los cuerpos graves tienen fu mo.

1 vimiento acia el centro de la tierra. 


\section{CONCLVSIONES}

2. Los cuerpos graves tienen inclinacion, $y$ movimiento al centro de la tierra, para com. poner juntos un globo total.

3. El globo terreftre no es grave.

4. El centro de la gravedad en el globo tertel. tre no fe muda.

\section{S. VI. \\ PREGVNT AS.}

1. POrque algunas Torres inclinadas no if
caen?

2. Porgue quando nos levantamos de una filla, inclinamos la cabeza, y pecho adelante. y retiramos los pies acia tras?

3. Como la cabeza anda mas que los pies?

4. Como puede un hombre tener tan altos lo pies como la cabeza?

5o Porque dos paredes lebantadas à perpendi culo nunca eltaràn paralelas?

PRE.

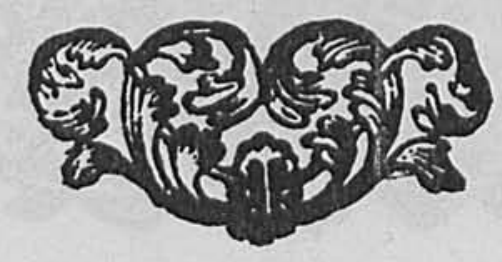


PRESIDIO EL CIRCO EL M. I.S. D. PEDRO MANVel de Arandia Governador, y Capitan General de eftas Islas Philipinas.

Tuvofe la Funcion en la Real, y Pontificia Vniverlidas de la Compañia de IESVS de efta ciudad de Manila dia del mes de Abril de 1758 .

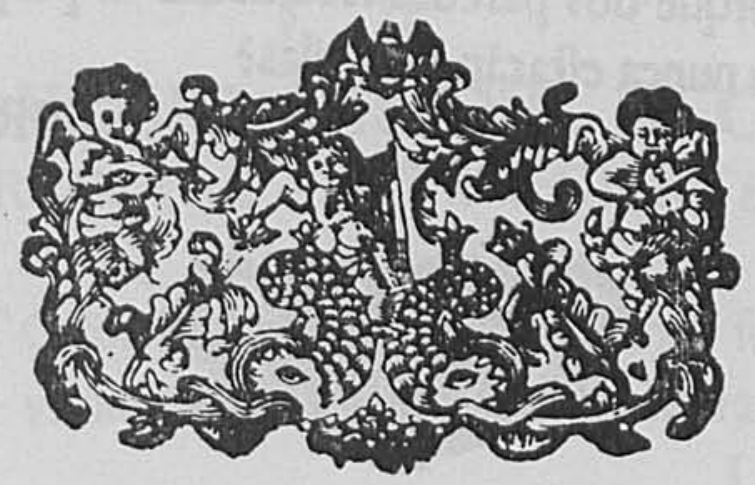


de la izquierda: Ha sido formado por Dios, padre del mundo (Sabiduria, 10-1), y la opuesta: Reina: la tierra se alboroce, alégrense muchas islas (Salmos, 96-1). En la parte superior, dos angelitos sostienen con una mano el escudo de España y con la otra un largo listón, en el que se leen otros versículos, cuya transcripción al castellano es la siguiente: Bendito el que viene Rey en nombre del Señor. Paz en el cielo y gloria en las alturas (Lucas 19-38), y: Lo adorarán todos los reyes de la tierra. En la parte inferior se extiende a todo lo ancho de la hoja una cartela con su respectiva leyenda: FERNANDO SEXTO REY DE ESPANA, Y EMPERADOR DE LAS INDIAS.

Bien trabajado está el dibujo del real personaje. Donoso, elegante, empuñando el cetro y luciendo el collar del Toisón, Fernando VI se nos aparece idealizado, embellecido y rejuvenecido con toda intención por la mano generosa del artista; pero la expresión del rostro aniñado es noble, simpática, amable. El retrato no traiciona, por lo menos sicológicamente, al original: "Fernando, sin poseer una fisonomia agradable, atraía por la dulzura de sus ojos azules y por cierta melancolía que como velo cubría todo su rostro, triste herencia de su padre. Podía encontrarse en sus movimientos y en la aptitud general de su cuerpo la irresolución que agobiaba con frecuencia su espíritu, y la indolencia, no efecto de la insensibilidad sino de la falta de vitalidad, que constituía el fondo de su carácter." 8

En cuanto al caballo, tiene soltura, movimiento, gracia; y el conjunto, en fin, nos da la impresión de armonía, equilibrio y aviso de que ya viene -aunque falte una distancia de medio siglo- trotando Carlos IV acompañado del genio de Tolsá. ¿Conocería el autor de este Fernando VI un grabado de la estatua ecuestre de Luis XIV realizada por Francisco Girardon (1628-1715?) No lo sabemos, aunque no está de más apuntar tal posibilidad.

Con letra diminuta, apenas legible, va señalada la paternidad de la ilustración que completó el texto de Araya: Bagay Scul. O sea, se dibujó y grabó en la misma casa impresora donde se tiraron las Conclusiones Mathemáticas, sin especificarse el nombre del modesto artista que realizó esta meritoria obra, a menos que hubiera sido el propio dueño de la imprenta, don Nicolás de la Cruz Bagay.

Aunque no tan elaborado ni igualado en calidad al monumental grabado de Lauriano Atlas que se publicó con la Theses de Memije,

8 Eduardo Chao, continuación de la Historia general de España del padre Mariana.. Imprenta y Librería de Gaspar y Roig, Editores, Madrid, 1854, t. Iv, p. 418. 
es eviclente que la idea que preside al dibujo que comentamos, está "menos jalada de los cabellos", menos rebuscada que la que animó a don Lauriano para dar forma a su complicado mapa. Y, sin embargo, ambas tareas responden a una idéntica motivación: mostrar o demostrar la universalidad, la grandeza mundial y el poderío -real y potencial, presente y futuro- de los dos hijos de Felipe $V$ que le sucedieron en el trono de España.

Que los autores intelectuales de semejante propaganda exageraban la nota, salta a la vista: la publicidad ya se ejercía con eficacia en el xvur; mas ello no invalida la conclusión final que nos merecen los curiosos e interesantes impresos filipinos rescatados para estos Anales después de más de dos siglos de dormir el sueño de los justos en los anaqueles de una biblioteca: son dos sillares de ese inmenso castillo de optimismo que se construyó en España durante el tiempo de la Ilustración, especialmente por los hombres que rodearon a Fernando VI y a Carlos III. Y fue tan resistente el edificio que, empezando a desgajarse en Trafalgar, no se pulverizó por completo sino hasta Cavité y Santiago de Cuba; es decir, casi a la vista del siglo $x \mathbf{x}$.

\section{DEDICATORIA DE LAS CONCLUSIONES MATHEMATICAS AL REY FERNANDO VI}

SENOR. Aún las Musas, con ser semideidades, no cantarán con empeño sin un Apolo que las llevase el punto, y en cuyas aras pudiesen suspender sonoros votos y consagrar religiosamente sus producciones harmónicas. Si por la malignidad de los injustos hados las llegase a faltar aquel gusto sublime del Numen Soberano, que se deja arrastrar de sus hechizos, creo que harían pedazos con desesperación contra una de las dos puntas del Parnaso, sus laúdes, sus harpas y sus liras; en ecchos temerosos de funestas endechas celebrarían todas lúgubres funerales a la Harmonía, o huérfana, o difunta; y en señal triste de su hondo sentimiento, se verian rodar con desperdicio por las quebradas de aquel Sagrado monte los gorjeos, los trinos, las piadas. Quiero decir, Señor, lo que ya V.M.G. ha penetrado: que si no hubiera Mecenas, tampoco hubiera Horacios ni Virgilios. A la más inocente jovialidad y decente eutrapelia entronizada en el ánimo real del Señor Philippe IV, Augusto Abuelo de V.M.G., debemos los Quevedos, los Montalvanes y todo el choro lúcido de poetas que supieron trasladar a Manzanares (el más pobre y el mús hidalgo de los ríos) las delicias de la Castalia, la Helicona y Aganipe, en la que podemos llamar edad dorada de Musas Españolas.

La misma fortuna han corrido hasta ahora las Ciencias Mathemáticis: aunque más nobles y mucho más necesarias que las Musas, desde 
el tiempo de su padre o restaurador, Euclides, viven sujetas a este hado, ni bien sé si propicio o miserable. Porque si Euclides las restituyó al mundo, con Euclides se hubieran enterrado, si un Ptolomeo Lago no las hubiera elevado hasta su Throno, y colocado cerca del Solio a Euclides con reales y soberanas atenciones. Los Clavios, los Kirkerios, los Lanis, los De-chales y tantos otros mantenedores ilustres del mundo Mathemático, no fueran hoy pasados, si para eternizarlos no hubieran alentado los bronces de la Fama, las protecciones augustas de los Gregorios XIII, Luises XIV, de un Phelipe V, Glorioso Padre de V.M.G.; en una palabra, las Coronas más elevadas, Eclesiásticas y Reales de la Europa? Esta conducta excelsa de los Reyes y aprobada de los Papas, ha mejorado mucho en manos del más amable y más amado de todos los Monarchas, que es V.M.G. (a quien cuadruplique el Cielo los de Nestor). Sabe ya todo el mundo con asombro que V.M.G. ha augmentado considerablemente el mayorazgo de España, haciendo tributarias a su Corona (además de las Facultades del Comercio y del más necesario mechanismo) las Ciencias Mathemáticas, a quienes son responsables las demás de su instrucción más precisa, y a quienes todas por ello rinden parias.

V.M.G. por colmo de la felicidad de su Reynado, ha logrado inspirar a sus Gobernadores; este espíritu es prueba muy ilustre de este influjo, la que ofrece vuestro Gobernador actual en estas Islas, Don Pedro Manuel de Arandia, el cual dando a entender que no sabe pensar, decir ni hacer sino lo más glorioso y acordado, no sabe acomodarse por la grandeza de su genio y elevación de su Espíritu, sino a seguir ejemplares coronados. Por esto ha tirado a emular en estas Islas, ejemplos majestuosos en todo lo demás, y muy particularmente en el celo (que ya parece interés por lo atesonado), y no es sino servicio de V.M.G., y llevarle su real genio, y en los cuidados menudísimos que ha querido emplear en promover en esta Ciudad el estudio Mathemático. $Y$ según es el empeño con que muestra haber hecho máxima de conduta la introducción de las Mathemáticas en este ángulo del mundo, bien declara su marcial conocimiento, que sin esta basa, no serán los frutos que desea del formado regimiento de la Infantería con el Real nombre de V.M.G., que con lustre y a expensas de su cuidado, le vivificó a la vista de la incredulidad, tan veterano a esfuerzos de su Espíritu, que sin diferencia a las demás huestes de los otros dominios, lo han manifestado los destacamentos que se han empleado; a que acompaña la navegación de los bajeles de este continente, por las reglas de su ordenanza, en que descuella tanto obelisco a la ceguedad celante de confrontar con el Real agrado de V.M.G., y no menos, según son superiores las atenciones y honores con que ha sido servido de distinguir entre el noble vecindario a estos vasallos de V.M.G., sus menores Oficiales, y primeros Profesores, bien podemos (debemos, quise decir) asegurarle a V.M.G. sin que llegue a entenderlo la lisonja, que vuestro Gobernador en solicitación de vuestras soberanas complacencias, os ha hecho un servicio en estas Islas, fomentando esta noble Academia, que le hace acreedor en la piedad de V.M.G. 
a que le añada a sus títulos el renombre de Euclides Philippino. Con efecto, sola su constancia pudiera haber vencido este imposible. La erección de una Ilustre Academia, y de Mathemáticas, en las Islas Philippinas, siempre fuera mirada (como se miró siempre) como una de aquellas especies que no pudiendo pasar desde las sutilezas de la especulación a las ejecuciones de la práctica, sólo podría ser útil para engrosar el partido de las ideas Platónicas en el cóncavo más profundo de la Luna. Pero ha mostrado a Manila su experiencia, que el vencimiento de imposibilidades, existimadas en el heroico character de vuestro Gobernador, práctica ordinaria de sus nobles alientos en el servivicio de V.M.G. y natural desahogo de aquel hercúleo esfuerzo de su corazón impertérrito, naturalmente magnánimo.

Si los límites de una Carta Dedicatoria de una obra tan pequeña como la que nos atrevemos a presentar a los pies de V.M.G no fueran tan reducidos, ¿qué ocasión más oportuna, Señor, para decir y no acabar sobre la arduidad, necesidad, utilidad e hidalguía de las Ciencias Mathemáticas? ¿Cuánto tendría que preconizar, si fuera yo capaz de ello, la Corona que ha ceñido V.M.G. de nuevo a las sienes de la Reyna de este su emporio Español en el Oriente (hablo de esta Capital) con esta nueva Ilustre Academia; con ella deja V.M.G. a la Nobilísima Giudad cuán soberanamente ennoblecida? Ya de hoy más por los desvelos de vuestro Gobernador y aplicación de vuestros Académicos, no tendrá este Comercio que recurrir al auxilio, tan forzoso hasta aquí como siempre sospechoso, de naciones extranjeras, para encontrar quien lieve y traiga con entera seguridad sus galeones, quien repare sus muros y los refuerze en los casos necesarios; quien sepa manejar con inteligencia en caso de invasión su artillería; quien hermosee sus fábricas militares y civiles; quien la beneficie en fin con mil especies de importantes inventos y servicios, que en bien de la civilidad y vida Republicana facilita en todas partes, donde no es peregrina esta noble Facultad, hija del Cielo. Baste apuntar, Señor, lo que para ensalzarlo justamente, requería una Iliada de elogios, repetida por otra Iliada de Lustros.

Reciba V.M.G. por manos de vuestro jefe y vuestro Capitán General (tan acostumbrado a manejar las armas para defenderle a V.M.G. con el crédito, que es público, su Corona), este don tan pequeño, como precioso en los ojos de V.M.G. Reciba V.M.G., con la benignidad que emplea en los Académicos de su Reyno, este parto primerizo de la fecundidad de esta Academia Asiática (para que se vea hasta dónde alcanza el influjo de las reales inclinaciones de V.G.M.), siquiera por llegar a sus reales pies desde tan lejos, puede ser que merezca con el nombre de obsequio peregrino, algunas realidades de estimado, tiene el honor de ofrecerlo a V.M.G. el menos circunstanciado de los muy honorables Académicos, que no aspira con esta leve significación de su respecto y grave testificación de su trabajo, si no es a merecerle a V.M.G. con este pequeño alarde militar sus superiores agrados. De ellos debe esperar la Academia naturalmente sus adelantamientos en el servicio de V.M.G. Acaso elevada un poco por el poderoso brazo 
de V.M.G., podrá hacer más visible desde más alta la fidelidad con que desea servir y la puntualidad de sus obsequios. Por estrena de los que debe a V.M.G. esta Ilustre Academia, le D.O.C. estas Theses Mathemáticas, cometiendo este honor incomparable, a el que por juzgarlo esta Academia capaz de sostenerlas con decoro, se las mandó defender públicamente, y es etc. Don Fernando de Araya. 